أثر رأس المال النفسي الإيجابي في نية ترك العمل في بعض الفنادق المصرية من خلال الإرتباط الوظيفي كوسيط سامح فياض

Sameh.fayyad@tourism.suez.edu.eg محمد زبنة

Mohammed.Zeina@tourism.suez.edu.eg

$$
\text { كلية السياحة والفنادق - جامعة قناة السويس }
$$

الملخص:

يهدف البحث إلى دراسة أثر رأس المال النفسي الإيجابي في نية ترك العمل من خلال استخدام مفهوم الارتباط الوظيفي

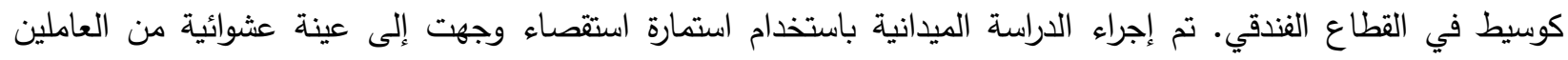

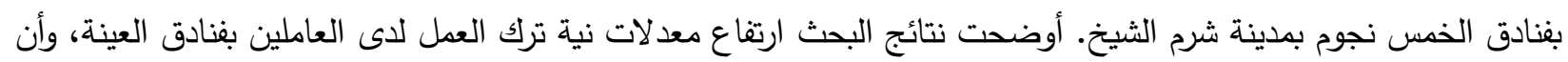

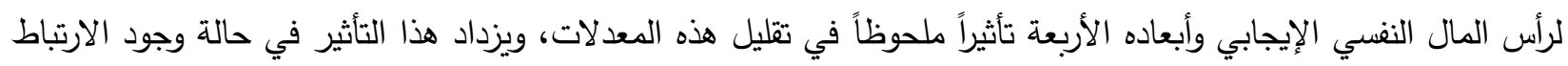

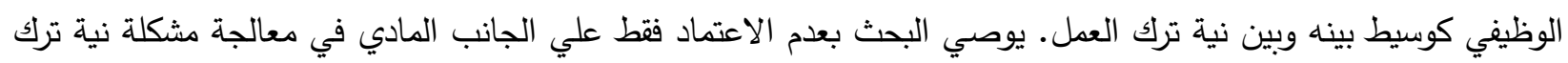

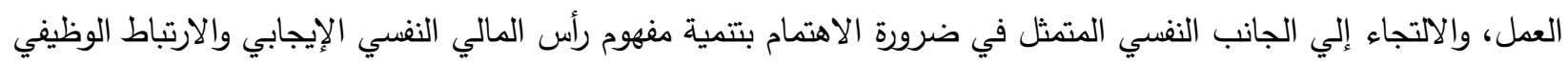
لإي العاملين.

الكلمات المفتاحية : رأس المال النفسي، الارتباط الوظيفي، نية ترك العمل، الكفاء الذاتية، الانغماس

المقدمة :

يعد ارتفاع معدل دوران العمالة أو نية العامل لترك العمل مشكلة شائعة ومكلفة في صناعة الضيافة، وترجع أسباب هذه المشكلة إلي عوامل مثل الأجر المنخفض، وساعات العمل اللاجتماعية Antisocial working hours، والأعمال العبودية Menial work، وفرص التحسن الوظيفي المحدودة Lub et al., 2012) limited career opportunities)،

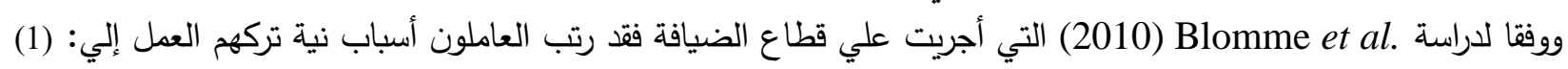

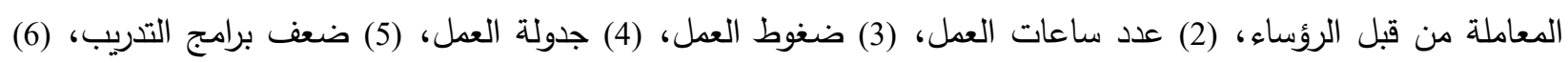

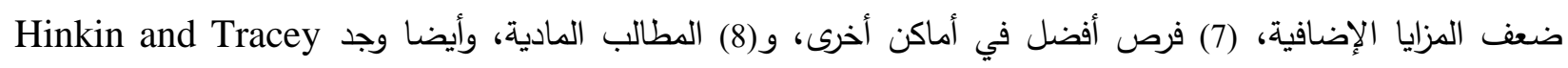

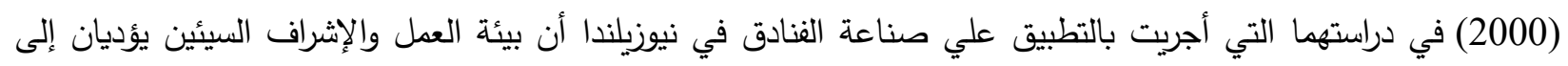

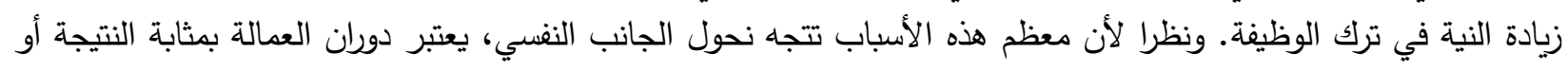

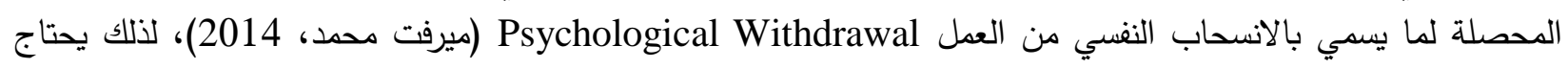

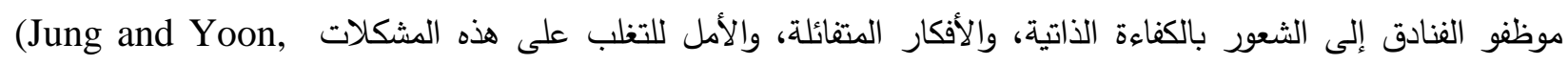

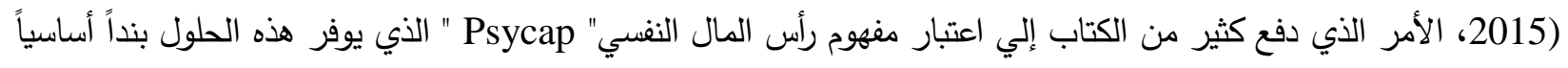

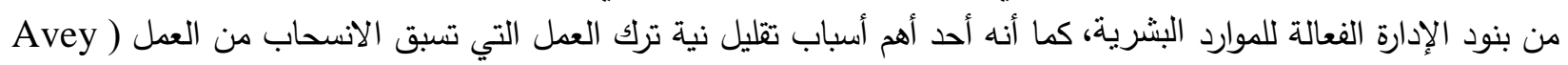
.et al., 2006

رأس المال النفسي الإيجابي Positive Psychological Capital (Psycap): يعد رأس المال النفسي من الاتجاهات الحديثة نسبيا التي بزغت في مجال إدارة الأعمال وبالأخص في حقل السلوك التنظيمي؛

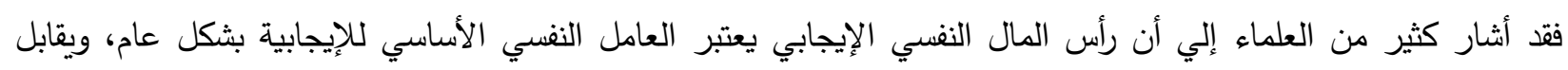

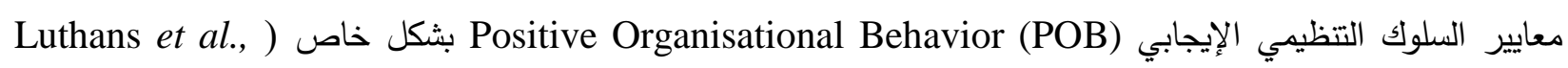

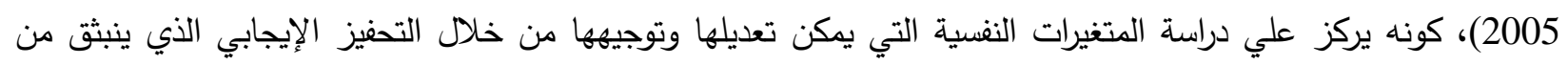

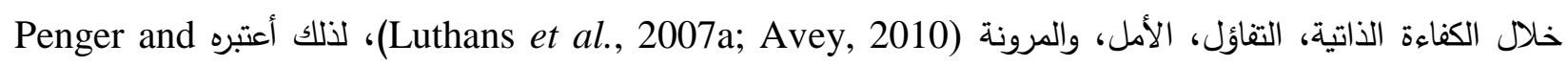
Authentic leadership ميعود الفضل والريادة للباحث ومجموعة من معاونيه قبل ما يربو علي عقد من الزمن في تطوير هذا المفهوم؛ إذ تمكنوا من الزج به

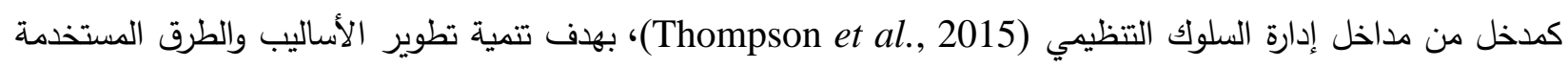
في إدارة رأس المال البشري. 
يعرف رأس المال النفسي الإيجابي بأنه "حالة التطور النفسي الإيجابي للفرد التي تتميز ب: (1) امتلاك الثقة (الكفاءة الذاتية)

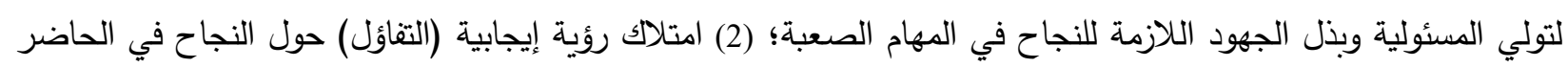

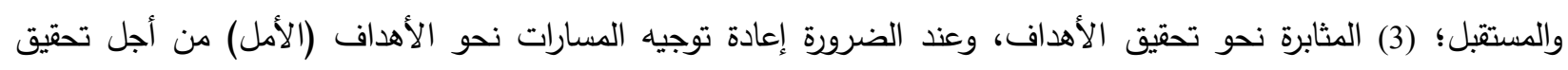
النجاح؛ و(4) عند التعرض للمشكلات والثدائد، يتم الارتداد إلي الوضع الطبيعي والاستمرار والمثابرة (المرونة) لتحقيق النجاح

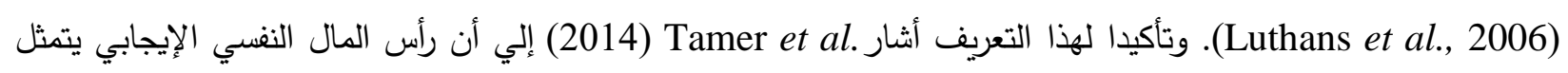

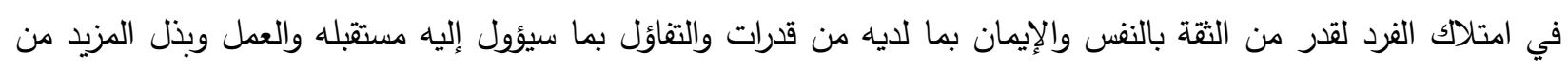
الجها بغية تحقيق الأهداف التي يصبو إليها معتمداً في سبيل تحقيق ذلك علي امتلاكه للمقدرة علي مواجهة المشكلات والصعوبات التي يواجهها في العمل.

ولذا يمكن القول بأن هذا المفهوم يرتبط بالإجابة عن تساؤلين مهين أولهما: من أنت؟ وثانيهما: ماذا تريد أن تكون مستقبلاً

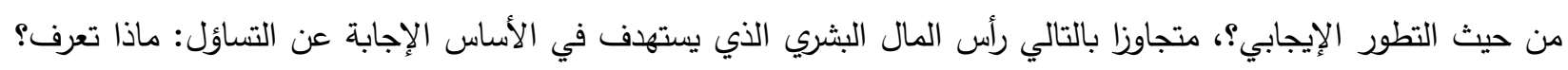
وكذا رأس المال الاجتماعي الذي يجيب عن من تعرف؟ (Luthans et al., 2008). تعتبر الموارد البشرية بالنسبة للمنشأة الفندقية مصدرا لبناء الميزة التتافسية (Onsoyen et al., 2009)، ومن ثم تظهر أهمية رأس المال النفسي الإيجابي في صناعة الضيافة كونه منهجا جديدا لإدارة الموارد البشرية مكن المدراء من الاستثمار في قدرات

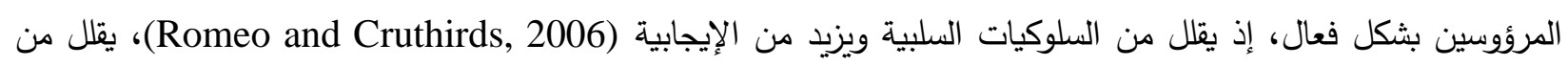

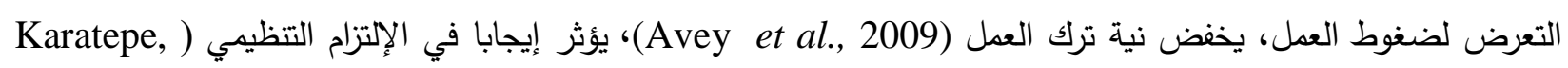

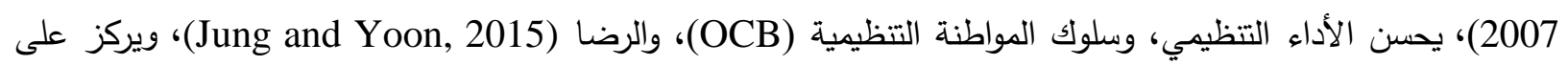
الجوانب الإيجابية للعاملين بدلاً من التركيز على نقاط الضعف ولاءل (محمد فوزي، 2017).

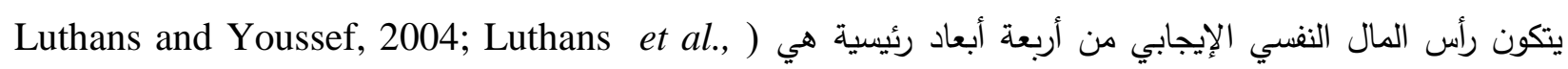
- :(2007b; McMurray et al., 2010 Self-efficacy : الكفاءة الذاتية عرف Luthans et al (2007b) الكفاءة الذاتية بأنها امتلاك العامل قدرا كافيا من الثقة بالنفس تمكنه من بذل الجهود اللازمة

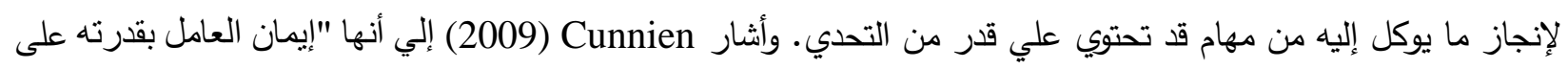
الوصول إلى الهحف"، وتوافر هذا القدر من ثقة العاملين بإمكاناتهم وقدراتهم يعزز من ارتباطهم بالمنشأة التي يعملون بها؛ حيث يشعرون بالراحة تجاه الأعمال والمهام التي يؤدونها لمجرد شعورهم أنهم سادة ما يؤدون (Thompson et al., 2015). ويري مصطفي محمد (2013) أن العامل قد يعتقد أنه غير قادر علي القيام بأعباء ومسئوليات وظيفة معينة دون تجربة أو تحقق من عدم مقدرته علي القيام بها، وهذا قد يكون بسبب انخفاض كفاءته الذاتية وليس بسبب عدم امتلاكه القدرات والإمكانيات اللازمة للقيام بمثل هذه الأعباء، الأمر الذي يزيد من شعور العامل بالاحتقان تجاه المنشأة التي يعمل بها.

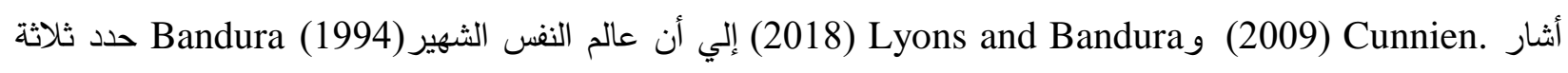

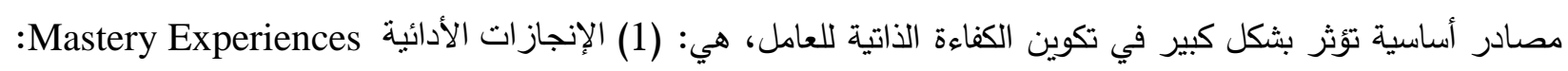

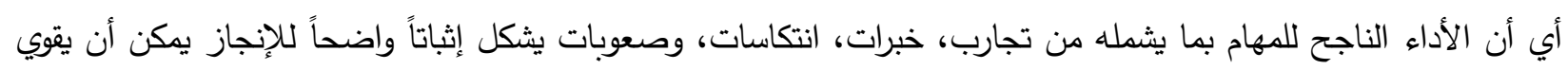
الإيمان بالكفاءة الذاتية، في حين أن الفشل في تحقيق النجاح قد يؤدي إلى الإضرار بها؛ (2) الإنهاء Persuasion ملاحظة النماذج القدوة Observation of Role Models: إذا لاحظ العامل نماذج مشابهة لنجاحه في المهام التي وكلت إليه، فإن ذلك يؤثر في معتقداته ودوافعه ويزيد من كفاءته الذاتية. 
هناك فارق كبير بين الأمل بالمفهوم التقليدي والأمل بمفهوم رأس المال النفسي الإيجابي، فالأمل بالمفهوم التقليدي يتمثل في

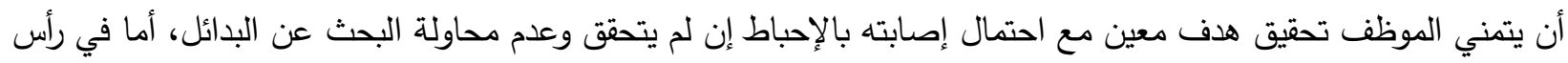

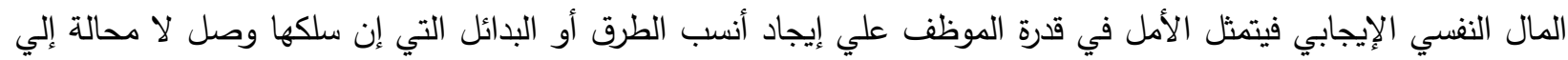
تحقيق ما يطمح إليه من أهداف (Luthans et al., 2007a). وبناءً عليه فالأمل بمفهوم رأس المال النفسي الإيجابي عبارة عن حالة تحفيزية إيجابية تستند إلي ثلاثة مكونات أساسية هي (Luthans et al., 2008; Han et al., 2012): (1) قوة الإرادة Will-power: وتعني الطاقة الموجهة نحو تحقيق

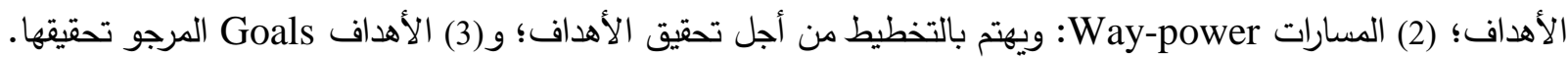
: Optimism 3 يمكن اعتبار التقاؤل بمثابة عماد رأس المال النفسي وذلك لارتباطه الكبير بما سوف يحدث مستقبلا للموظف من أحداث قد

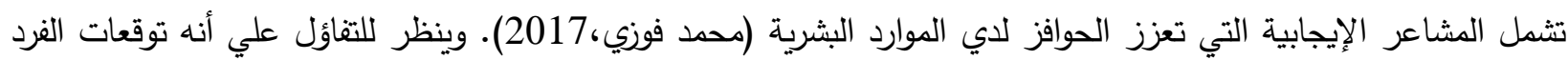
الإيجابية للمواقف والأحداث المستقبلية، ومن ثم فعند حدوث نتائج سلبية يحافظون علي دوافعهم لتحقيق النتائج الإيجابية (صفاء أحمد ومحمد جمال، 2016). ويمكن القول إنه بدون امتلاك العامل القدر الكافي من التفاؤل يتضاءل انتماؤه للمنشأة التي يعمل بها (Thompson et al., 2015). : Resiliency المرونة 4 تعرف المرونة بأنها "نمط من التكيف الإيجابي أثناء أو بعد الثدائد أو المخاطر الثديدة التي يتعرض لها العامل ( Masten (et al., 2009; Han et al., 2012 لابد أن يمتلك العامل القدرة علي الارتداد أو استعادة التوازن والعودة سريعا إلي الوضع الطبيعي (Luthans et al., 2006).

الإرتباط الوظيفي Work Engagement (WE) ظهر هذا المفهوم في أوائل القرن الحادي والعشرين، وعرف بأنه "الحالة الذهنية التي يبدي فيها العامل أثثاء العمل اهتماماً مفعما بالحيوية، والإخلاص، الحماسة" (Schaufeli and Bakker, 2004)، ويتميز بثلاث خصائص أساسية هي الحيوية

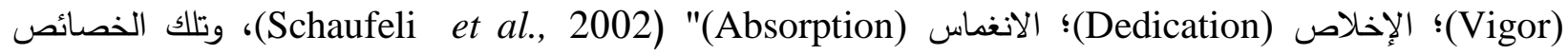

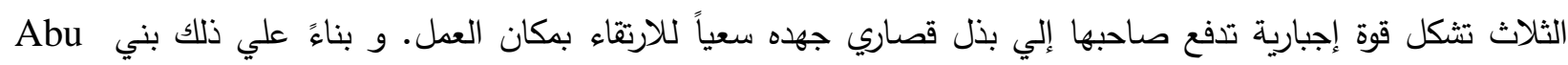

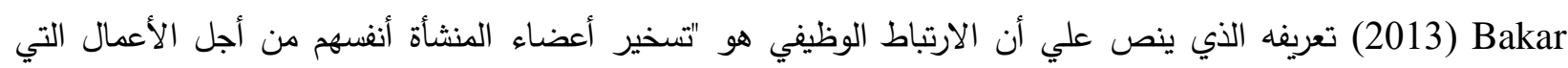

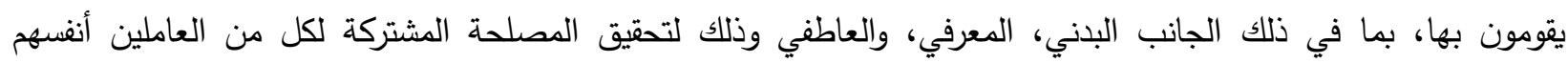
والمنشأة التي يعملون بها". وبناءً علي ما ذكر آنفا يعد الارتباط الوظيفي بمثابة العمود الفقري للنجاح التنظيمي لأي منشأة؛ فالعاملون الأكثر ارتباطاً

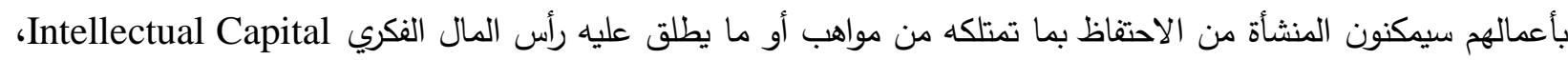

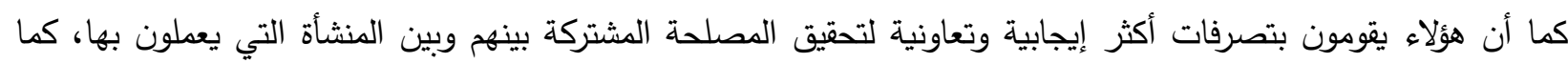

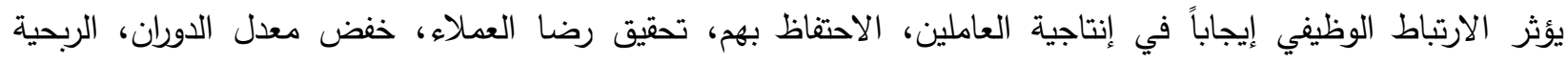
الإجمالية (Penger and Černe, 2014)، ويعمل كذلك علي خلق مناخ قائم علي الاحترام والثقة بين العاملين؛ والارتقاء

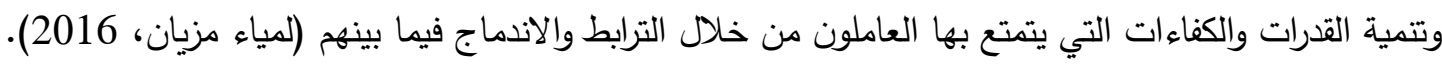
يقسم العاملون إلي ثلاثة أنواع طبقا لمستوي ارتباطهم الوظيفي بحسب (Cataldo, 2011) وهي: (1) العمالة المرتبطة بالمنشأة Engaged: وهم يتميزون بمستويات أداء عالية باستمرار، الابتكار والإبداع، دوافع ذاتية لبناء وتحقيق الكفاءة، فهم واضح

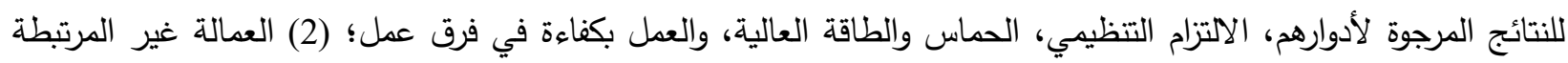
بالمنشأة Not Engaged: هؤلاء يقومون بتأدية ما قد يطلب منهم من مهام فقط، ولا يقومون بأي أدوار إضافية، ولا يشغلهم 
تحقيق أهداف المنشأة، ويبررون ذلك بأنهم لا يشعرون بدورهم وجدوي ما يقومون به من أعمال، ويشعرون بعدم التقدير من

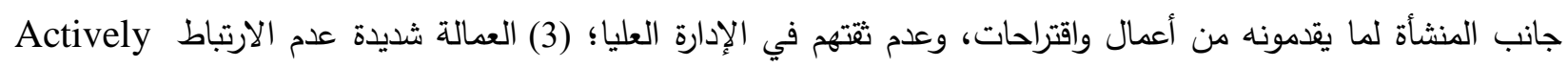

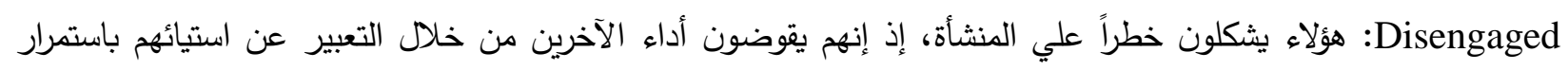

عن وظائفهم. ولكن يمكن للإدارة تحويل النوعين الأخيرين إلي الأول من خلال توفير المناخ الذي من شأنه أن يسمح للموارد البشرية بإنجاز

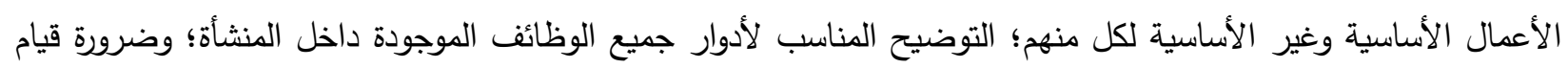
القائد بإزالة الحواجز والقيود بينه وبين مرؤوسيه.

\section{العلاقة بين رأس المال النفسي الإيجابي والارتباط الوظيفي ونية ترك العمل ولئل}

Karatepe and Karadas, 2015; Jung ) قليل من الدراسات تتاولت مفهوم رأس المال النفسي في أدبيات إدارة الضيافي تركئ (and Yoon, 2015 ولذلك تسعي هذه الورقة البحثية إلي سد هذا الفراغ من خلال ربط رأس المال النفسي بالارتباط الوظيفي ونية ترك العمل. وفيما يتعلق بالعلاقة بين رأس المال النفسي والارتباط الوظيفي ففي دراسة Karatepe and Karadas (2015) التي أجريت علي صناعة الضيافة في رومانيا تم استخدام الارتباط الوظيفي كوسيط بين رأس المال النفسي والرضا

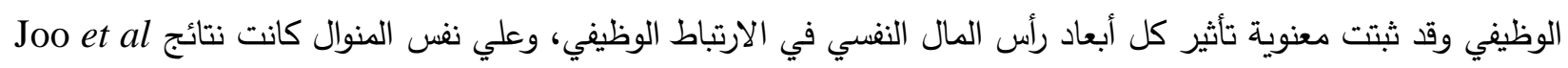

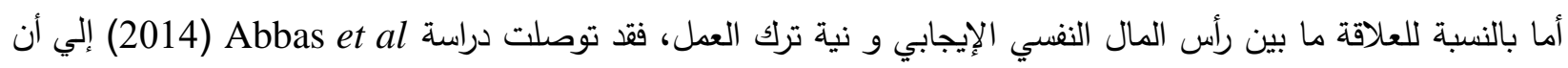

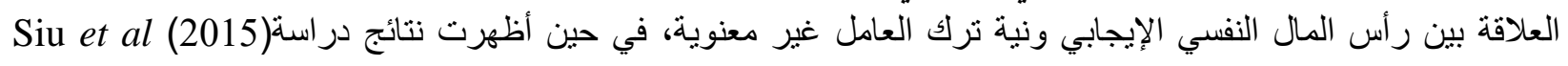

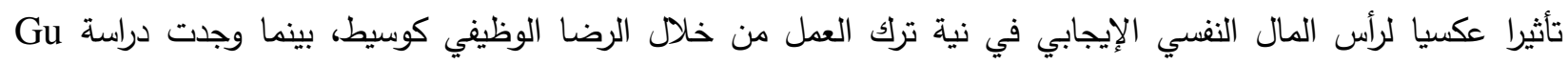

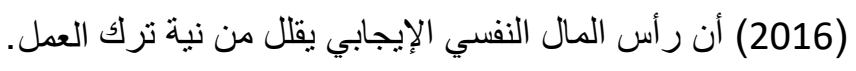
وعلي الجانب الآخر أكدت نتائج دراسة Saks (2006) على العلاقة الإيجابية بين الارتباط بالعمل والالتزام التتظيمي، ووجود

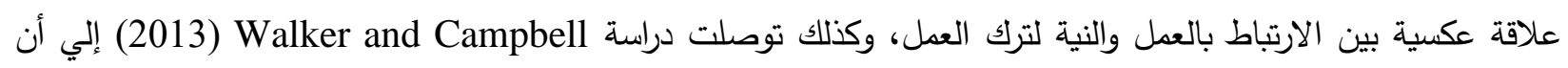
الارتباط بالعمل توسط العلاقة بين الفطنة التتظيمية Organizational Acumen والنية في البقاء في العمل، ولذا أشارت

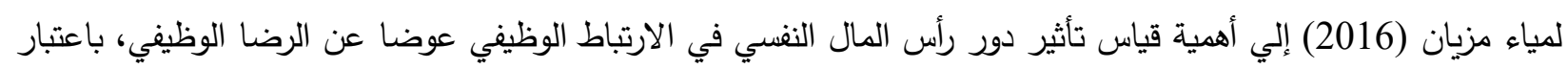

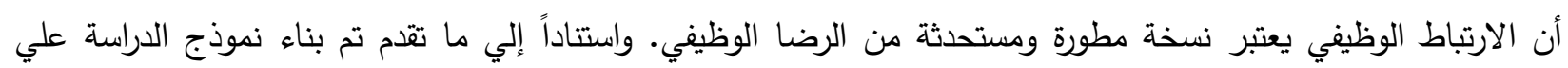

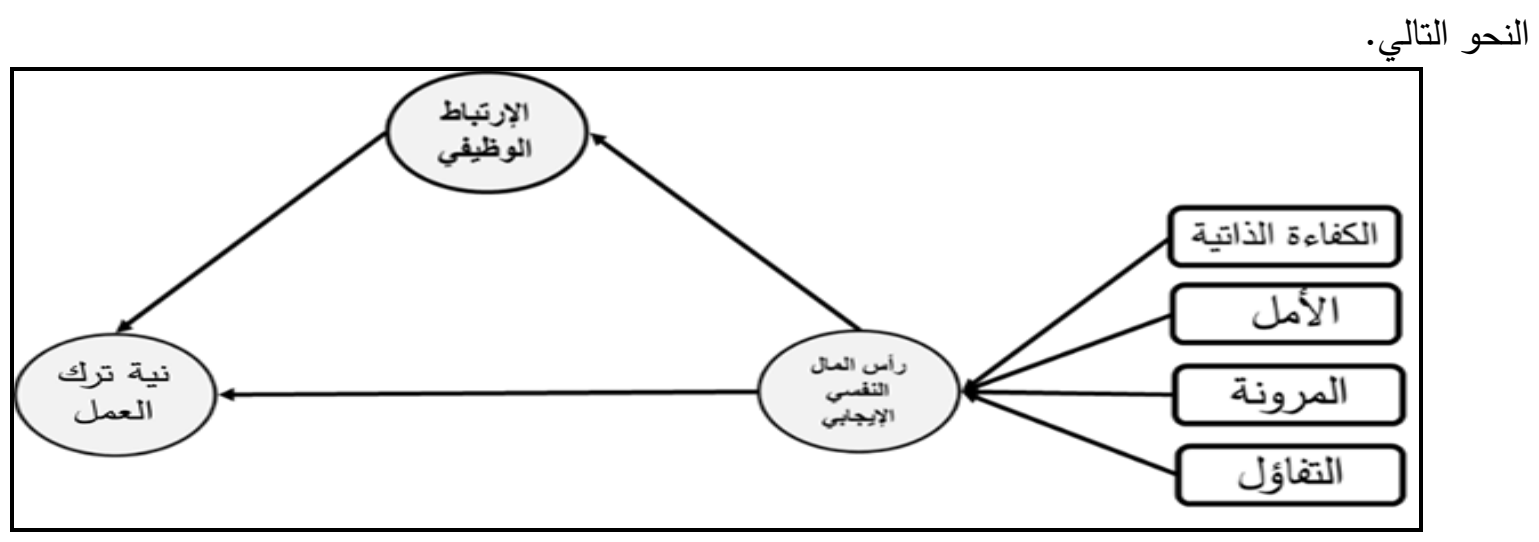

شكل (1) النموذج المقترح للعلاقات بين متغيرات البحث

فروض الدراسة

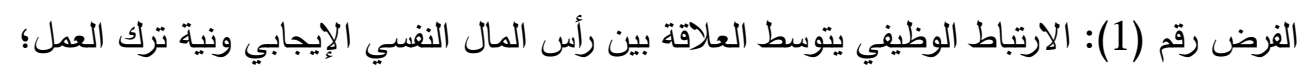

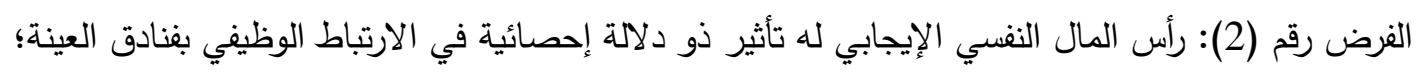
الفرض رقم (3): الارتباط الوظيفي له تأثير ذو دلالة إحصائية في نية ترك العمل بفنادق العينة. 
تم تحديد مجتمع البحث في بعض فنادق ومنتجعات مدينة شرم الثيخ فئة الخمس نجوم (20 فندقا) كعينة احتمالية عشوائية، جمعت البيانات باستخدام استمارة استقصاء (500) وزعت على العاملين بفنادق (قسمي الأغذية المشروبات والمكاتب

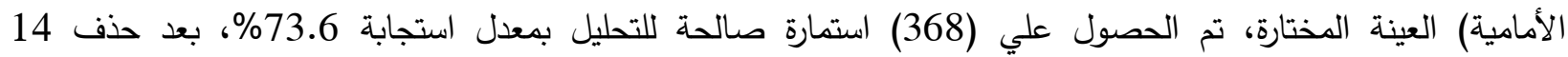
استمارات لاحتوائها علي العديد من البيانات المفقودة. تم استخدام برنامج SPSS نسخة 22 لمعالجة البيانات المفقودة، القيم المتطرفة Outliers، والتأكد من العلاقة الخطية بين مفردات الدراسة وإجراء انحدار بين بعض متغيرات الدراسة. واختبرت الفروض بطريقة المربعات الصغرى الجزئية باستخدام برنامج SmartPLS3. وقد شملت استمارة الإستقصاء 26 مفردة؛ تم تخصيص ست عشرة مغردة الأولي لأبعاد رأس المال

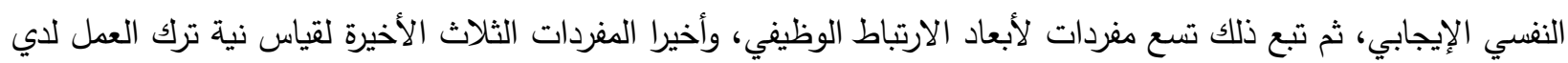

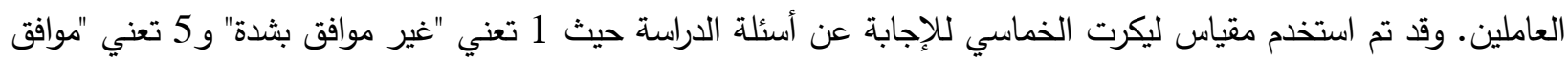

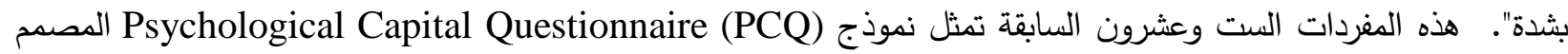

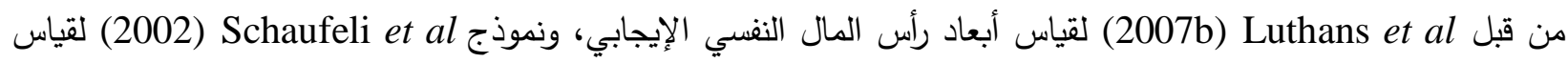

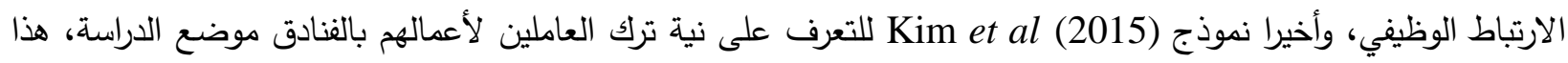
وقد تم عمل دراسة استطلاعية مسبقة Pilot Study من خلال عرض الأداة على بعض المتخصصين ذوي الخبرة للتأكد من

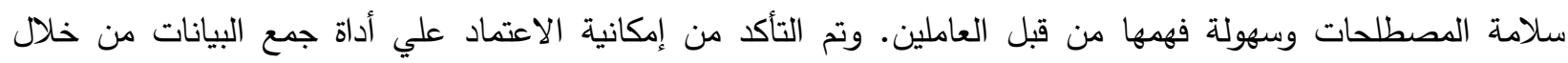
استخدام معامل ألفا كرونباخ Cronbach's Alpha لاختبار ثبات مقاييس الدراسة والاتساق الداخلي، فقد تراوحت قيمه بين 0.84 و0.97 كما هو موضح بجدول (1)، وهي بذلك تزيد عن الحد الأدنى المقبول إحصائياً (0.7).

النتائج والمناقثة

تم اختبار نموذج وفروض الدراسة باستخدام طريقة المربعات الصغرى الجزئية Partial Least Square (PLS) باستخدام Structure Equation Modelling برنامج SmartPLS3، وتعد هذه الطريقة أحد أساليب نماذج المعادلة الهيكلية عادل (SEM)، وأهم ما يميزها أنها صالحة للاستخدام في حالة بناء النظريات وكذلك في حالة اختبار النظريات على حد سواء)

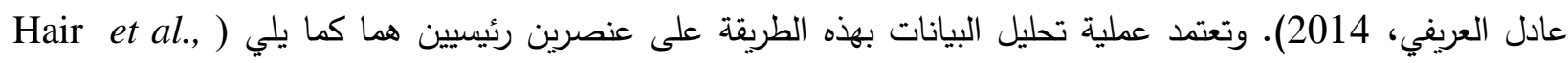

أولا: تقييم نموذج القياس Measurement model أو النموذج الخارجي Outer Model لتتحقق جودة نموذج القياس في طريقة المربعات الصغرى الجزئية لابد من توافر بعد الثروط، هي كما يلي:-

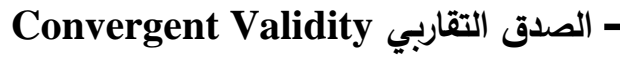

يشير الصدق التقاربي إلي مدى تقارب وتوافق أسئلة القياس مع بعضها البعض عند قياس نفس البعد، كما يثير إلي أن

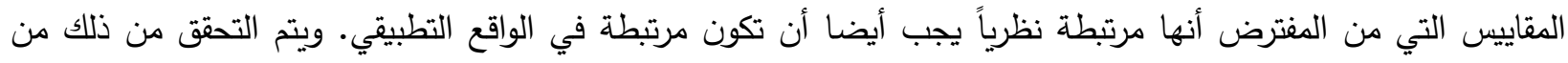

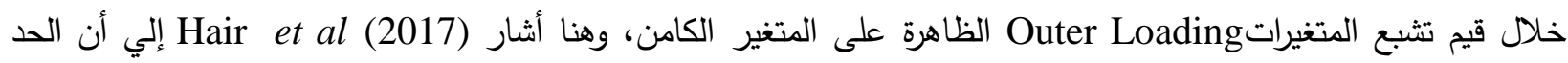

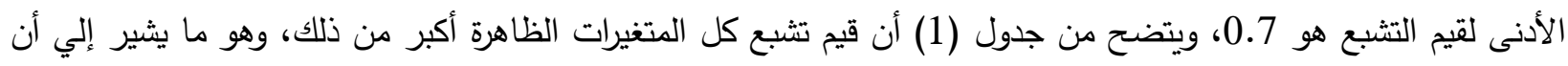
كل متغير ظاهر استخدم لقياس بعد الكفاءة الذاتية مثلا قادراً على قياسه، وقد ثبتت معنوية جميع قيم التشبع عند وكانت قيمة T-Value الدحسوبة أكبر من قيمتها الجدولية 1.96. ولتأكد أيضا من تحقق الصدق التقاربي يجب أنساء أن تكون

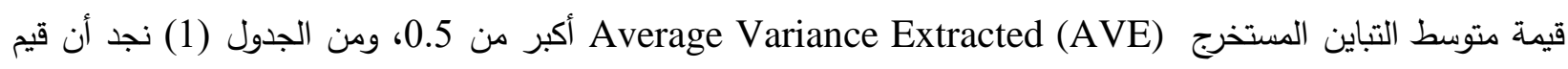

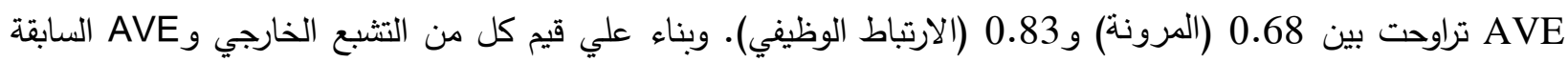

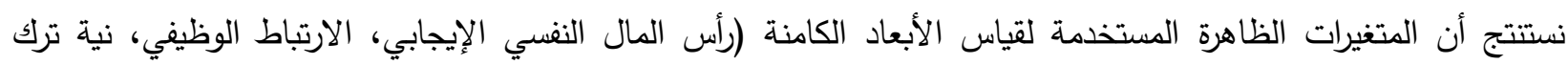
العمل) يتوفر بها الصدق التقابي وهي الأفضل لقياسها، كما أنها مترابطة في الواقع التطبيقي. 
- الثبات التركيبي (Composite reliability (CR)

أستخدم الثبات التركيبي لقياس ثبات العوامل الغير ظاهرة أو الكامنة، ويجب أن تكون قيمته أكبر من 0.7، ومن الجدول (1) نجد أن كل قيم CR لكل العوامل الكامنة أكبر من 0.7 فقد تراوحت بين 0.89 و0.98، وبذلك يمكن الوثوق بالأبعاد المستخدمة في هذه الدراسة وتكراراها في دراسات مستقبليه.

جدول (1) إحصائيات تقييم نموذج القياس والمتوسط الحسابي والانحراف المعياري

\begin{tabular}{|c|c|c|c|c|c|c|c|c|}
\hline 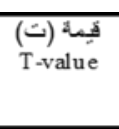 & \begin{tabular}{c|} 
Outer \\
Outer \\
Loadings
\end{tabular} & الالاندر افي & الكستوبط & 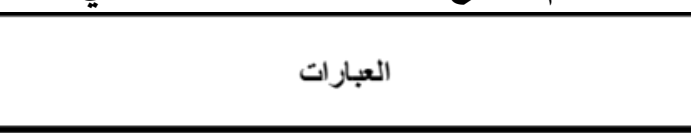 & الألئبات & 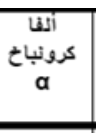 & 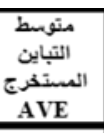 & المتانيريات \\
\hline 50.25 & 0.88 & 0.77 & 2.79 & لاي الثقة في تحليل المشكلات التي تواجهني وحلها & \multirow{4}{*}{0.92} & \multirow{4}{*}{0.88} & \multirow{4}{*}{0.73} & \multirow{4}{*}{ الذاتية } \\
\hline 33.07 & 0.86 & 0.66 & 2.86 & أشعر بالثقة غد تمثيل زملاثي في الاجتماعات & & & & \\
\hline 39.93 & 0.86 & 0.72 & 2.79 & أشعر بالثقة في إسهامي في رسم استراتيجية قسمي. & & & & \\
\hline 30.35 & 0.83 & 0.71 & 2.71 & أشعر بالثقة في المساعدة علي تحليد وصياغة أهداف قسمي. & & & & \\
\hline 45.46 & 0.89 & 0.83 & 2.76 & لاي الإمكانية في التفكير بالمسارات الكفيلة لتجاوز ضغط العمل. & \multirow{4}{*}{0.94} & \multirow{4}{*}{0.91} & \multirow{4}{*}{0.80} & \multirow{4}{*}{ الأمل } \\
\hline 35.37 & 0.86 & 0.82 & 2.74 & في الوقت الحالي أتابع أهدافي بثكل نشيط في قسمي. & & & & \\
\hline 103.98 & 0.95 & 0.78 & 2.66 & أري نفسي كشخص ناجح جدأ في عملي & & & & \\
\hline 41.81 & 0.87 & 0.79 & 2.73 & لاي القدرة على التفكير بعدة أشكال لتحقيق أهافي. & & & & \\
\hline 19.92 & 0.80 & 0.68 & 2.69 & لاي مرونة عالية في التعافي عند مواجهة العقبات & \multirow{4}{*}{0.89} & \multirow{4}{*}{0.84} & \multirow{4}{*}{0.68} & \multirow{4}{*}{ 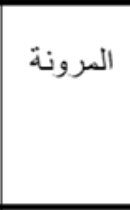 } \\
\hline 29.04 & 0.85 & 0.76 & 2.54 & أتعامل مع الظروف الصعبة (الضغوط) بشكل أو بآخر & & & & \\
\hline 52.13 & 0.90 & 0.70 & 2.56 & لدي مرونة في مواجهة الأحداث المرهقة لمواجهتي مثلها سابقاً & & & & \\
\hline 15.97 & 0.73 & 0.72 & 2.68 & لدي الإمكانية في تجاوز الطروف الصعبة في العطل لمواجهتها مسبقاً & & & & \\
\hline 23.51 & 0.83 & 0.72 & 2.56 & غذما تكون حالات من اللحتأكد في عملي، غالباً ما أتوقع الأفضل. & \multirow{4}{*}{0.94} & \multirow{4}{*}{0.91} & \multirow{4}{*}{0.79} & \multirow{4}{*}{ التفاؤل } \\
\hline 47.85 & 0.89 & 0.71 & 2.66 & من الحكمة حدوث الأخطاء في العمل وهو أمر طبيعي. & & & & \\
\hline 51.17 & 0.90 & 0.74 & 2.63 & عالباً ما أنظر إلى الجانب المشرق في عملي. & & & & \\
\hline 80.18 & 0.92 & 0.76 & 2.63 & أنا متفائل بشأن الأحداث المستقبلية بخصوص علي. & & & & \\
\hline 79.21 & 0.91 & 0.99 & 3.01 & غنما أستيقظ في الصباح أشعر برغبة في الأهاب إلي العمل & \multirow{9}{*}{0.98} & \multirow{9}{*}{0.97} & \multirow{9}{*}{0.83} & \multirow{9}{*}{ الارتباط } \\
\hline 53.96 & 0.89 & 1.00 & 3.02 & أشعر بطاقة وحيوية كبيرة في عملي & & & & \\
\hline 111.06 & 0.93 & 0.97 & 3.00 & أشعر بالقوة والنثاط في عملي & & & & \\
\hline 54.52 & 0.88 & 0.91 & 3.00 & عملي يلهمني ويحفزني & & & & \\
\hline 66.36 & 0.89 & 0.97 & 2.99 & أنا متحمس لعملي & & & & \\
\hline 70.27 & 0.90 & 0.99 & 3.03 & 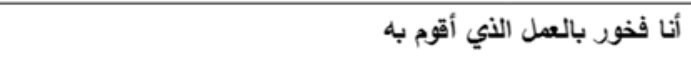 & & & & \\
\hline 97.41 & 0.93 & 0.99 & 3.04 & غذما أعل فأنني أنسي كل شيء من حولي & & & & \\
\hline 80.26 & 0.92 & 0.96 & 3.02 & أنا منغمس كليا في عملي & & & & \\
\hline 80.28 & 0.92 & 0.98 & 3.04 & أكون سعيدا غذما أعمل بشكل مكثف & & & & \\
\hline 63.36 & 0.91 & 0.70 & 4.53 & أفكر في ترك الوظيفة & \multirow{3}{*}{0.93} & \multirow{3}{*}{0.89} & \multirow{3}{*}{0.82} & \multirow{3}{*}{ نبة ترك ك } \\
\hline 69.03 & 0.93 & 0.69 & 4.60 & لاي نية للاستقالة & & & & \\
\hline 44.81 & 0.89 & 0.68 & 4.56 & لاي نية للبحث عن وظيفة جليدة. & & & & \\
\hline
\end{tabular}

- صدق التمايز Discriminant validity

صدق التمايز هو على النقيض بشكل كامل مع الصدق التقابي، ويهدف إلي قياس مدى التباعد أو التتافر المنطقي لأدوات

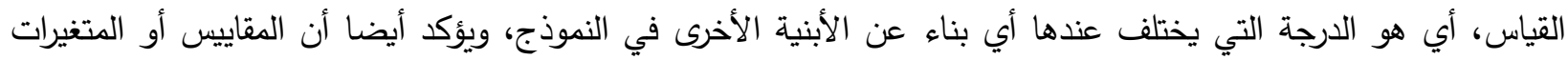

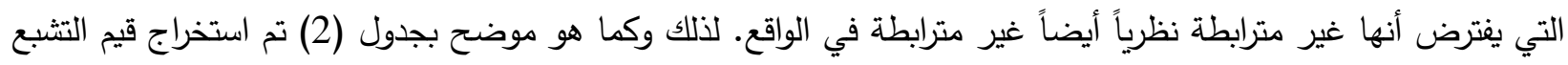
المتداخل Cross-Loading ووجد أن قيمتها أقل من قيم التشبع الخارجي Outer loading (المميزة بخط أسفها)، وهذا يؤكد أن المتغيرات الظاهرة لكل بعد كامن تختلف كليا عن المتغيرات الظاهرة للأبعاد الكامنة الأخرى المستخدمة في النموذج، فالأسئلة المخصصة لقياس بعد الأمل مثلا لا تقيس إلا هو . 
أثر رأس المال النفسي الإيجابي في نية ترك العمل في بعض الفنادق المصرية من خلال الإرتباط الوظيفي كوسيط

جدول رقم (2) تحليل معامل الصدق التمييزي Outer loading و Cross-Loading

\begin{tabular}{|c|c|c|c|c|c|c|}
\hline الأمل & الوظيفي & التفاؤل & الذاتية & المرونـة & العمالة & \\
\hline 0.635 & 0.207 & 0.422 & 0.888 & 0.490 & -0.109 & psych capital 1 \\
\hline 0.520 & 0.243 & 0.401 & 0.878 & 0.409 & -0.044 & psych_capital_2 \\
\hline 0.558 & 0.340 & 0.368 & $\overline{0.870}$ & 0.566 & -0.167 & psych_capital_3 \\
\hline 0.544 & 0.292 & 0.430 & 0.848 & 0.512 & -0.128 & psych capital 4 \\
\hline$\underline{0.895}$ & 0.209 & 0.416 & 0.527 & 0.407 & -0.133 & psych_capital_5 \\
\hline 0.871 & 0.224 & 0.410 & 0.599 & 0.435 & -0.109 & psych_capital_6 \\
\hline 0.950 & 0.377 & 0.452 & 0.609 & 0.549 & -0.186 & psych_capital_7 \\
\hline$\underline{0.883}$ & 0.433 & 0.465 & 0.599 & 0.585 & -0.218 & psych_capital_8 \\
\hline 0.460 & 0.239 & 0.467 & 0.551 & 0.819 & -0.105 & psych capital 9 \\
\hline 0.475 & 0.384 & 0.571 & 0.504 & 0.870 & -0.222 & psych_capital_10 \\
\hline 0.487 & 0.354 & 0.463 & 0.502 & $\underline{0.916}$ & -0.158 & psych_capital_11 \\
\hline 0.448 & 0.250 & 0.481 & 0.353 & 0.771 & -0.111 & psych_capital_12 \\
\hline 0.337 & 0.318 & $\underline{0.845}$ & 0.461 & 0.490 & -0.178 & psych_capital_13 \\
\hline 0.473 & 0.273 & $\underline{0.902}$ & 0.398 & 0.594 & -0.094 & psych capital_14 \\
\hline 0.450 & 0.296 & $\underline{0.915}$ & 0.404 & 0.468 & -0.096 & psych_capital_15 \\
\hline 0.476 & 0.347 & $\underline{0.931}$ & 0.414 & 0.553 & -0.163 & psych_capital_16 \\
\hline 0.329 & $\underline{0.940}$ & 0.314 & 0.264 & 0.357 & -0.706 & Absorption_1 \\
\hline 0.307 & 0.929 & 0.353 & 0.218 & 0.332 & -0.714 & Absorption 2 \\
\hline 0.298 & 0.924 & 0.329 & 0.261 & 0.355 & -0.694 & Absorption 3 \\
\hline 0.365 & 0.897 & 0.316 & 0.289 & 0.342 & -0.746 & Dedication_1 \\
\hline 0.336 & 0.905 & 0.316 & 0.392 & 0.341 & -0.737 & Dedication_2 \\
\hline 0.316 & $\underline{0.911}$ & 0.305 & 0.336 & 0.345 & -0.695 & Dedication_3 \\
\hline 0.327 & 0.919 & 0.290 & 0.279 & 0.322 & -0.690 & Vigor 1 \\
\hline 0.324 & 0.905 & 0.295 & 0.243 & 0.297 & -0.693 & Vigor_2 \\
\hline 0.300 & $\overline{0.941}$ & 0.319 & 0.277 & 0.335 & -0.778 & Vigor 3 \\
\hline-0.189 & -0.746 & -0.174 & -0.084 & -0.180 & 0.946 & Turnover_1 \\
\hline-0.174 & -0.746 & -0.153 & -0.150 & -0.134 & $\overline{0.955}$ & turnover 2 \\
\hline-0.152 & -0.722 & -0.088 & -0.133 & -0.193 & 0.932 & turnover 3 \\
\hline
\end{tabular}

ويمكن التأكد أيضا من صدق التمايز عن طريق معامل Fornell-Larcker الذي يستخرج بحساب الجذر التربيعي لمتوسط التباين المستخرج AVE لكل متغير (Hair et al., 2017)، إذ يجب أن تكون قيمته أعلي من القيم المرتبطة به في الصفوف

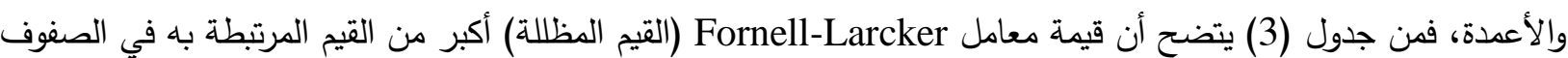
والأعمدة، وفقدت تراوحت القيم بين 0.82 و 0.91 في حين كانت قيم الارتباط بين 0.344 و 0.798 0.

جدول(3) متوسط التباين المستخرجAVE،المتوسط والانحراف المعياري،معاملات الارتباط بين متغيرات الدراسة، وصدق التمايز

\begin{tabular}{|c|c|c|c|c|c|c|c|c|c|c|}
\hline \multirow{2}{*}{ نرنّة } & \multirow{2}{*}{ الارتباط } & \multicolumn{4}{|c|}{ رأس المال النفسي الإيجابي } & \multirow{2}{*}{ الانحر اف } & \multirow{2}{*}{$\begin{array}{c}\text { الحسابي } \\
\text { الحتوسط } \\
\text { الحس }\end{array}$} & \multirow[b]{2}{*}{ AVE } & \multirow[b]{2}{*}{ الأبعاد ال } & \multirow{2}{*}{ الرئيسية } \\
\hline & & التفاؤل & المرونة & الأمل & الذاتية & & & & & \\
\hline & & & & & 0.86 & 0.613 & 2.79 & 0.73 & الكفاءة الذاتية & \\
\hline & & & & 0.89 & $.587^{* *}$ & 0.718 & 2.72 & 0.80 & الأمل & \\
\hline & & & $\mathbf{0 . 8 2}$ & $.446^{* *}$ & $.470^{* *}$ & 0.588 & 2.62 & 0.68 & المرونة & النسسي \\
\hline & & 0.89 & $.519^{* *}$ & $.367^{* *}$ & $.344^{* *}$ & 0.648 & 2.62 & 0.79 & التفاؤل & \\
\hline & 0.91 & $.479^{* *}$ & $.543^{* *}$ & $.504^{* *}$ & $.512^{* *}$ & 0.884 & 3.02 & 0.83 & لا بالعمل & الارن \\
\hline 0.91 & $-.798^{* *}$ & $-.509^{* *}$ & $-.579^{* *}$ & $-.567^{* *}$ & $-.579^{* *}$ & 0.628 & 4.56 & 0.82 & & نبة \\
\hline
\end{tabular}




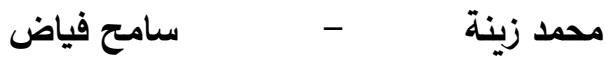

ثانيا: تقييم نموذج الدراسة المقترح Assessment of Structural Model

ويعنى نموذج البناء أو النموذج الداخلي بدراسة العلاقات بين المتغيرات الكامنة ذاتها ( وهي التي تمثل فروض الدراسة). ووفقا Hair (2017) فهناك بعض الاشتراطات لتأكد من صحة النتائج، ومن ثم يمكن اختبار الفروض وهي:-

- إثبات صحة وساطة الارتباط الوظيفي بين رأس المال النفسي الإيجابي ونية ترك العمل

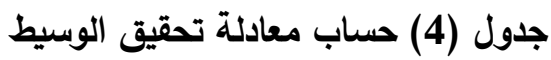

\begin{tabular}{|c|c|c|c|c|c|c|}
\hline \multirow[t]{2}{*}{ Psycap -> WE } & \multirow[t]{2}{*}{ WE -> Turnover } & \multirow{2}{*}{ العلاقة غبر } & \multirow{2}{*}{ الانحرياري } & \multirow{2}{*}{ قيمة (ت) } & \multicolumn{2}{|c|}{ Bootstrapped Confidence Interval } \\
\hline & & & & & $95 \% \mathrm{LL}$ & $95 \%$ UL \\
\hline 0.667 & -0.568 & -0.379 & 0.044 & -8.622 & -0.465 & -0.293 \\
\hline
\end{tabular}

يتضح من جدول (4) أن قيمة أعلي مستوي هي (UL=-0.293) وقيمة أقل مستوي هي (LL=-0.465) لا يقع بينهما الصفر وبالتالي يتحقق شرط صحة الوسيط، وبذلك يكون الارتباط الوظيفي وسيطا بين رأس المال النفسي الإيجابي ونية ترك هي هئك

العمل)(Preacher and Hayes, 2008).

- معامل التحديا (2)

يلاحظ بالثكل (2) أن قيمة معامل التحديد لنية ترك العمل كمتغير تابع قد بلغت (R²=0.707) مما يعني أن كلا من رأس المال النفسي الإيجابي والارتباط الوظيفي قادران علي تفسير 71\% تقريبا من التغير في معدل نية ترك العمل والباقي يرجع لعوامل أخري، وهذا يؤكد القوة التقسيرية لنموذج الدراسة ويدعم قبوله وتعميمه، إذ يذكر عادل العريفي، (2014) أنه إذ كانت قيمة (R2 $)$ فإنها تدل علي القوة التفسيرية للنموذج المستخدم.

Cohen (F⿻) يظهر معيار كوهين قدرة تقسير كل متغير مستقل علي حدة لمتغير التابع، تكون قيمته ضعيفة عند مستوى 0.02 أو أقل، ومتوسطة عند مستوى 0.15 أو أقل، وقوية عند مستوي أكبر من 0.15. ومن جدول فئرئ (5) نجد أن رأس المال النفسي الإيجابي

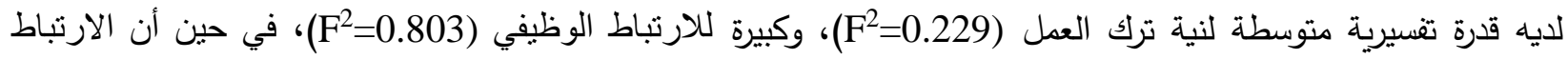
الوظيفي لديه قدرة تفسيرية كبيرة لنية ترك العمل (F²=0.610). وبالتالي يمكن استخدامه النموذج المقترح لاختبار فرضيات الدراسة واستخلاص النتائج والخروج بالتوصيات.

Cohen (F²) جدول (5) اختبار حجم التأثير

\begin{tabular}{|c|c|c|}
\hline الارتباط الوظيفي & نية ترك العمل & \\
\hline 0.803 & 0.229 & رأس المال النفسي الإيجابي \\
\hline & 0.610 & الارتباط الوظيفي \\
\hline
\end{tabular}

- اختبار ارتباط الأهمية التبوئية يجري اختيار Q للتعبير عن القوة التتبؤية للنموذج، ويجب أن تكون قيمته أكبر من (0.0) وكلما زادت القمة زادت الأهمية بحد أقصي (1) صحيح (عادل العريفي، 2014). وقد بلغت قيمة Q2 للارتباط الوظيفي ترك العمل 0.560، وهذا مؤشر علي القوة التتبؤية الجيدة للنموذج . - ماختبار الفرض الأول بالاطلاع علي النتائج بجدول (6) وشكل (2) نجد أن قيمة بيتا بلغت (Pكاول (P)0.000) في حالة العلاقة المباشرة بين رأس المال النفسي الإيجابي ونية ترك العمل، وهذا يعني أن رأس المال النفسي الإيجابي يؤثر عكسياً

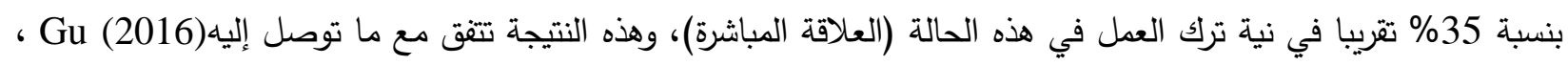
وأيضا مع النتائج الموضحة بجدول (1) حيث تثير دلالات المتوسطات الخاصة بمتغير رأس المال النفسي الإيجابي وأبعاده

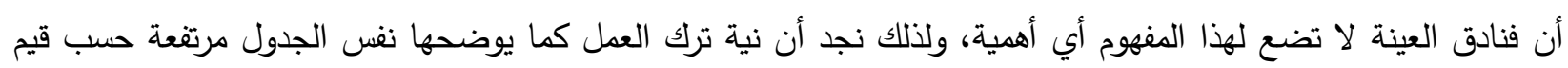


أثر رأس المال النفسي الإيجابي في نية ترك العمل في بعض الفنادق المصرية من خلال الإرتباط الوظيفي كوسيط

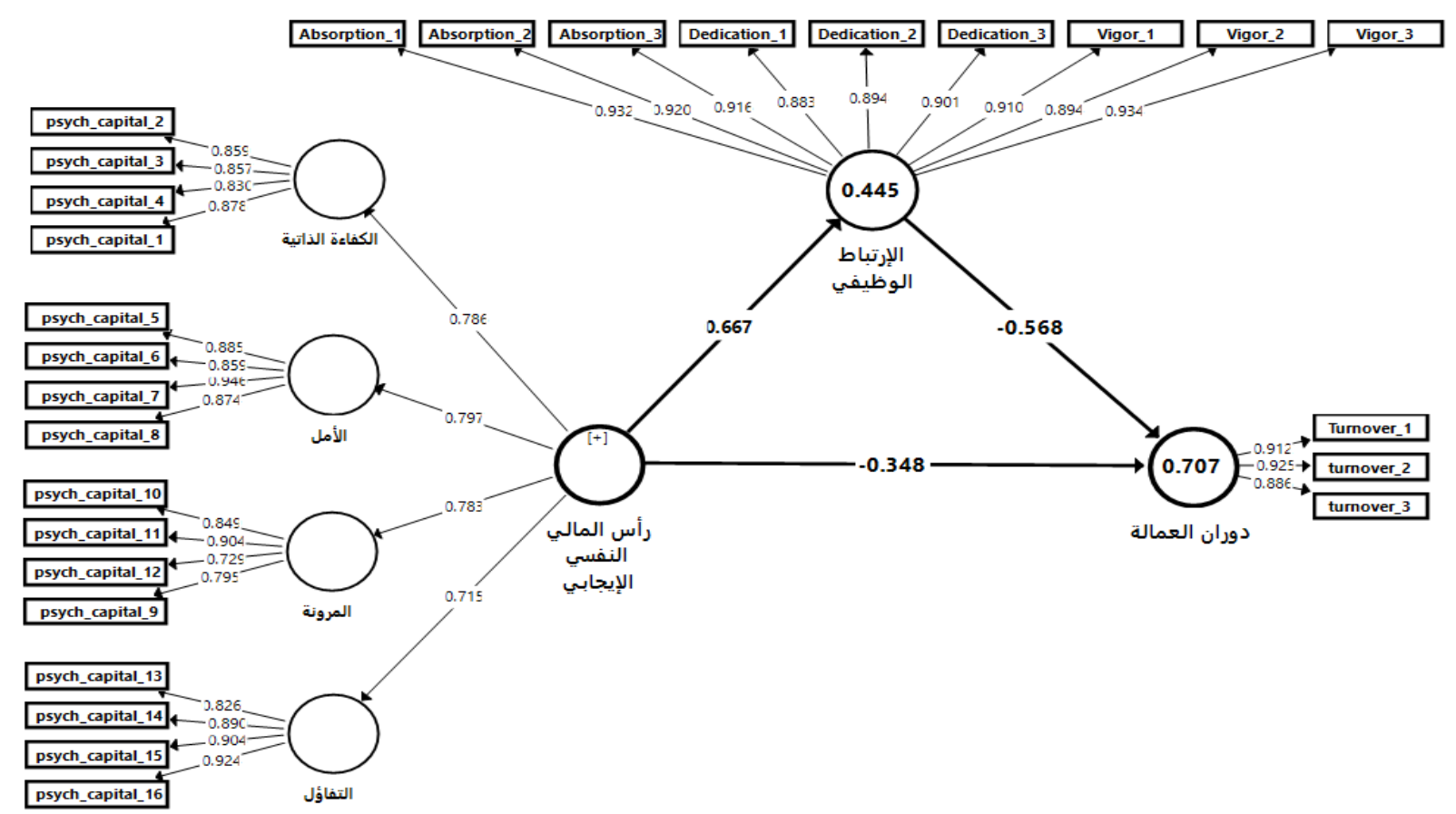

SmartPLS شكل (2) النموذج الهيكلي لفروض الاراسة المستخرج من برنامج

وعلي الجانب الآخر نجد أن قيمة بيتا بلغت (P>0.000) (P) في حالة العلاقة غير المباشرة

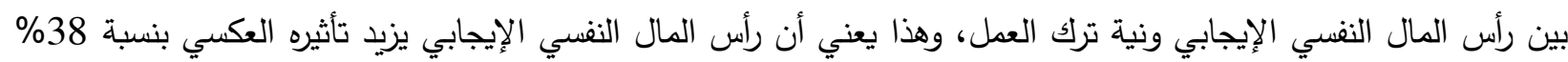
تقريبا في نية ترك العمل في حالة وساطة الارتباط الوظيفي بينهما، وهذه النتيجة تتماشي مع رأي لمياء مزيان (2016) القائل بأن رأس المال النفسي والارتباط الوظيفي مرتبطان بشكل كبير ببعضهم البعض.

جدول (6) نتائج تحليل المربعات الصغرى الجزئية PLS للعلاقة بين رأس المال النفسي الإيجابي ونية ترك العمل

\begin{tabular}{|c|c|c|c|}
\hline المعنوية.Sig & قيمة (ت) & م بيتا & الفرض \\
\hline $0.000^{* * *}$ & 6.347 & -0.348 & رأس المال النفسي الإيجابي -> نية ترك العمل (العلاقة المباشرة) \\
\hline $0.000^{* * *}$ & 8.622 & -0.379 & غرير المباشرة) النسي الإيجابي -> الارتباط الوظيفي -> نية ترك العمل (العلاقة \\
\hline $0.000^{* * * *}$ & 18.407 & -0.727 & 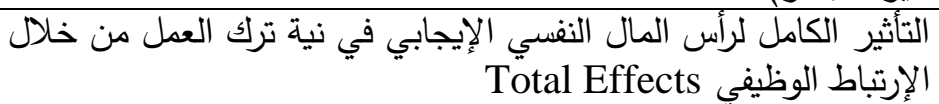 \\
\hline
\end{tabular}

وإجمالا للعلاقتين السابقتين وكما هو موضح بجدول (6) أن قيمة بيتا في حالة التأثير الكامل Total Effect (3) (3)=0.711)

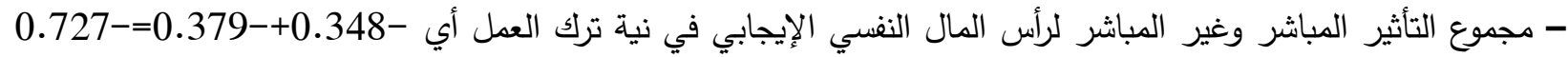
- وبذلك يزداد التأثير العكسي لرأس المال النفسي الإيجابي في معدل نية ترك العمل من 35\% إلي 73\% بـ تقريبا، إذا نجح

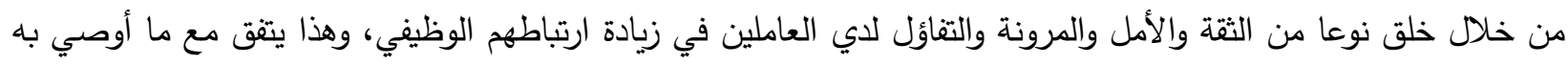
من Jung and Yoon.

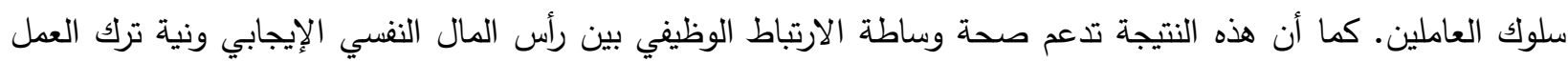

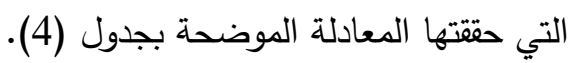
وعلي سبيل التفصيل يوضح جدول (7) أثر أبعاد رأس المال النفسي الإيجابي في نية ترك العمل، ونجد أنها جميعا متقاربة،

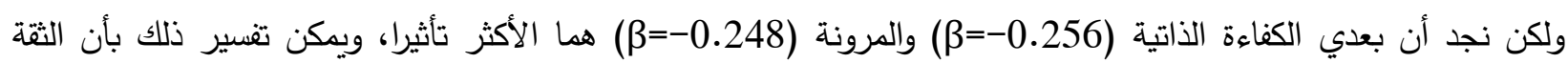
المكتسبة من الكفاءة الذاتية والمرونة في التعافي من الانتكاسات تخلق التفاؤل مما يزيد الأمل لدي العاملين وبالتالي تزيد فرصة نية البقاء بالعمل. وعموماً يمكن التأكيد علي أهمية مفهوم رأس المال النفسي الإيجابي بثكل متكامل في تقليل معدل نية الثية

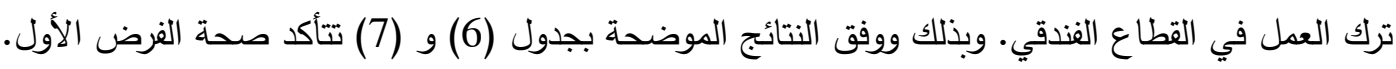


جدول (7) تحليل نموذج الانحدار المتعدد لتأثير أبعاد رأس المال النفسي الإيجابي في نية ترك العمل.

\begin{tabular}{|c|c|c|c|c|c|c|c|}
\hline للمتغير ات مجنمعنة الإجمالية & ف (F) & $\begin{array}{c}\text { معامل التحديد } \\
\left(\mathrm{R}^{2}\right)\end{array}$ & المصامل التحديد & T-value & المعنوية & رقم بيتا(及) & المتغير ات \\
\hline \multirow{4}{*}{$0.000^{* * * *}$} & \multirow{4}{*}{73.435} & \multirow{4}{*}{.528} & \multirow{4}{*}{.520} & -4.670 & 0.000 & -.256 & الكفاءة الذاتية \\
\hline & & & & -4.225 & 0.000 & -.230 & الأمل \\
\hline & & & & -4.600 & 0.000 & -.248 & المرونة \\
\hline & & & & -4.126 & 0.000 & -.208 & التفاؤل \\
\hline
\end{tabular}

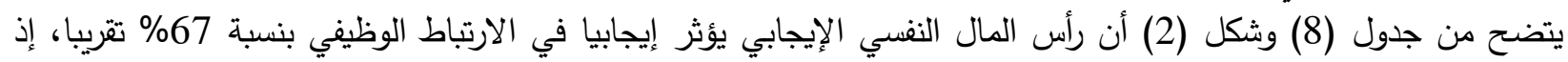

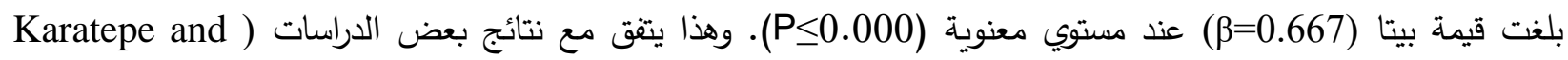
. (Karadas, 2015; Joo et al., 2016 جدول (8) نتائج تحليل المربعات الصغرى الجزئية PLS لأثر رأس المال النفسي الإيجابي في الإرتباط الوظيفي وأبعاده

\begin{tabular}{|c|c|c|c|}
\hline Sig. المعنوية & قيمة (ت) & 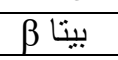 & الفرض \\
\hline $0.000^{* *}$ & 16.842 & 0.667 & رأس المال النفسي الإيجابي -> الارتباط الوظيفي \\
\hline
\end{tabular}

وتفصيلا يتضح من جدول (9) أن بعد المرونة أحد أبعاد رأس المال النفسي الإيجابي هو الأكثر تأثيرا في تحقيق الارتباط

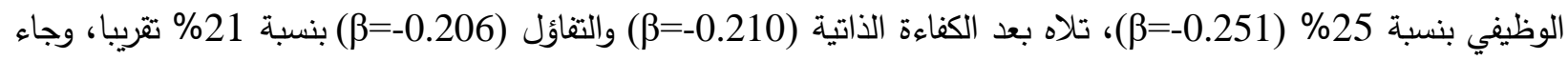

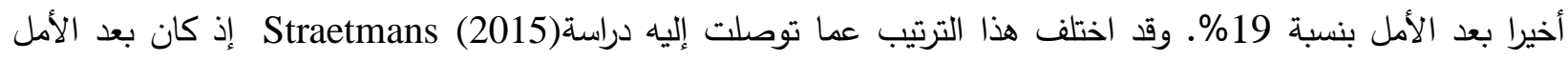

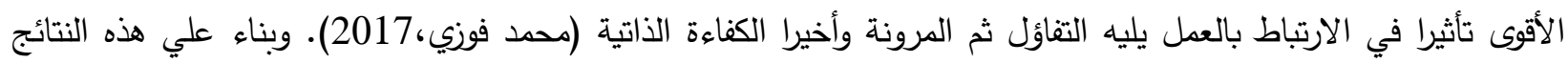

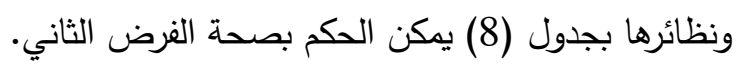

جدول (9) تحليل نموذج الانحدار المتعدد لتأثير أبعاد رأس المال النفسي الإيجابي في الارتباط الوظيفي.

\begin{tabular}{|c|c|c|c|c|c|c|c|}
\hline للمتغير ات مجنمعالية الإجمالية & ف (F) & 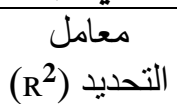 & المعامل التحديد & T-value & المعنوية & رقم بيتا(及) & المتغير ات \\
\hline \multirow{4}{*}{$0.000^{* * *}$} & \multirow{4}{*}{51.669} & \multirow{4}{*}{.440} & \multirow[b]{4}{*}{.432} & 3.520 & .001 & .210 & الكفاءة الذاتية \\
\hline & & & & 3.275 & .001 & .194 & الأمل \\
\hline & & & & 4.275 & .000 & .251 & المرونة \\
\hline & & & & 3.744 & .000 & .206 & التفاؤل \\
\hline
\end{tabular}

ـ - اختبار الفرض الثالث

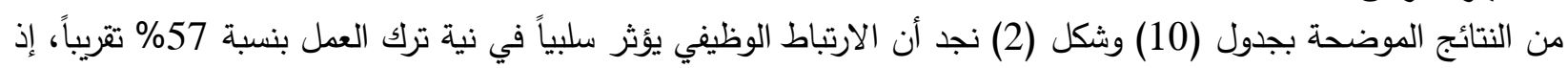

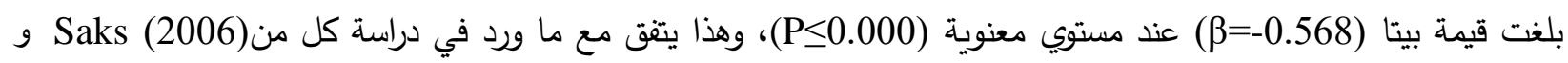
(Walker and Cambell (2013) ، وبذلك تتأكد صحة الغرض الثالث. جدول (10) نتائج تحليل المربعات الصغرى الجزئية PLS لأثر الإرتباط الوظيفي في نية ترك العمل

\begin{tabular}{|c|c|c|c|}
\hline المعنوية . Sig. & قيمة (ت) & 及 & الفرض \\
\hline $0.000^{* * * *}$ & 10.478 & -0.568 & -> نية ترك العمل \\
\hline
\end{tabular}

الخلاصة والتوصيات تفاقمت مشكلة نية ترك العمل أو دوران العمالة في الفنادق المصرية، مما أدي إلي فقدان الكثير من المواهب وتحمل الكلفة

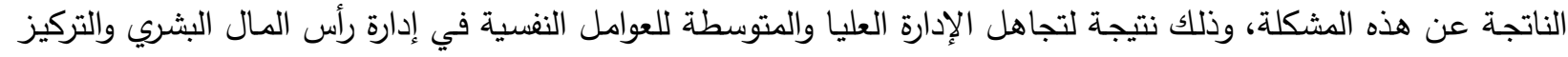

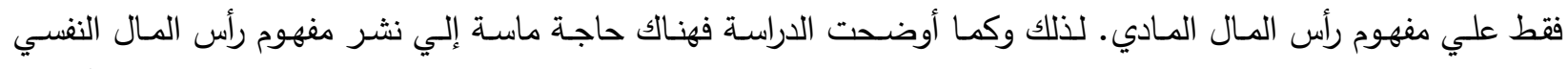

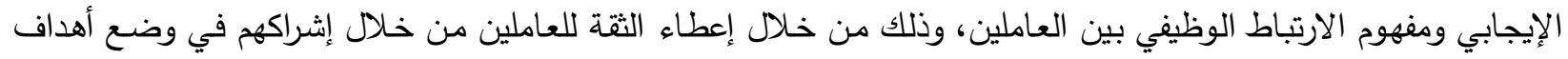

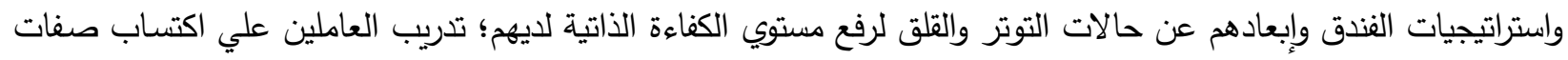

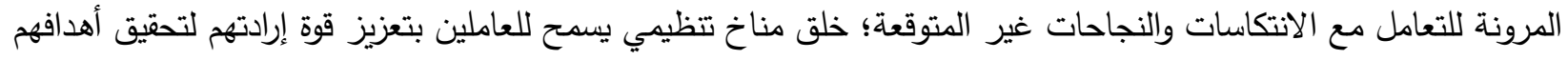

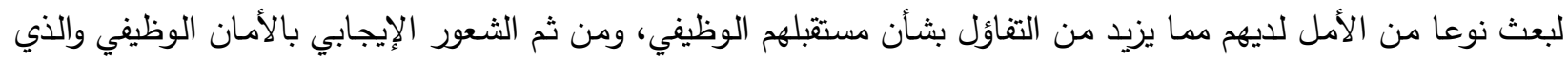

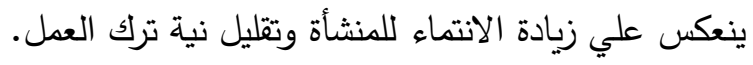


- - صفاء أحمد الثربيني ومحمد جمال عبدالقادر عوض (2016) "العلاقة بين أبعاد رأس المال النفسي وسلوكيات المواطنة

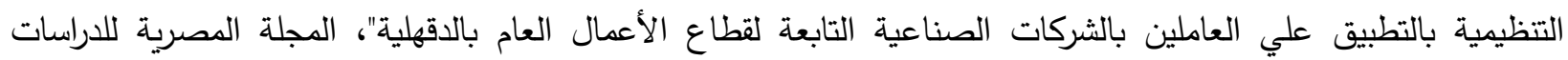

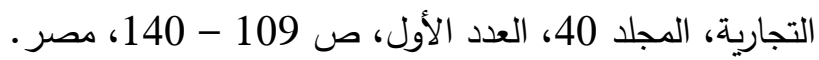

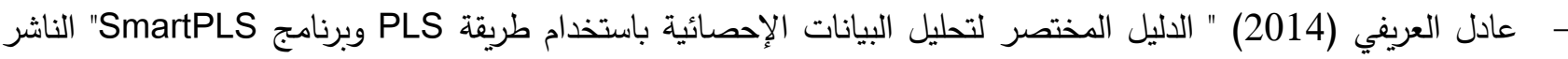
مركز Quality Research، الإصدار الأول، استراليا.

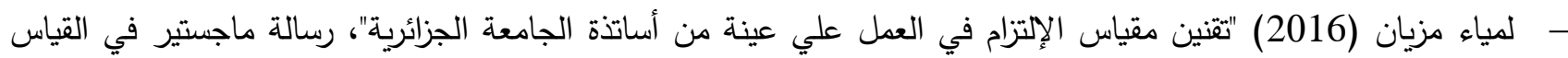

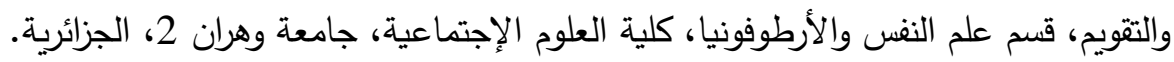

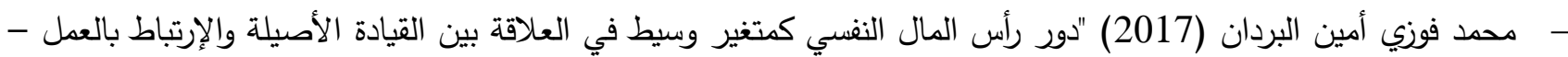

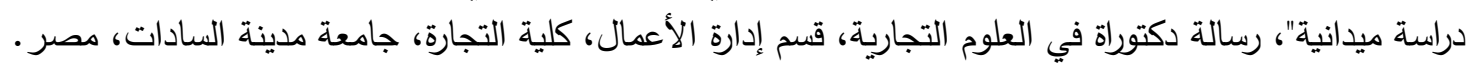

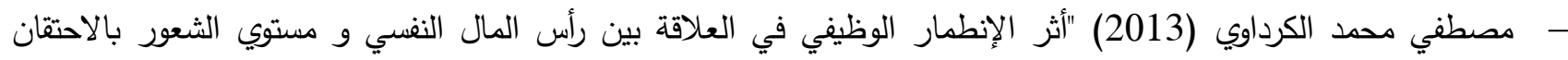

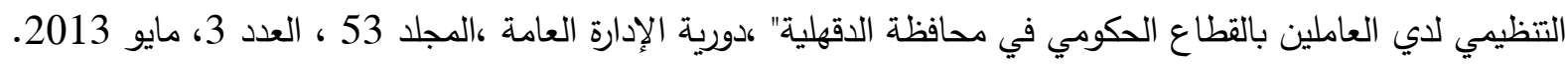

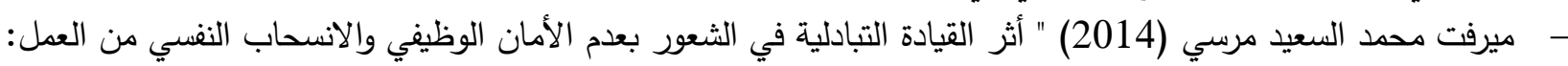

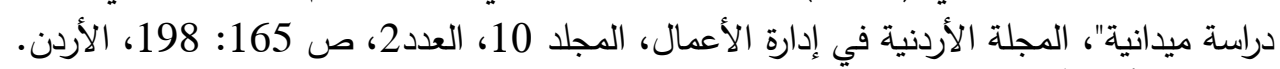

- Abbas, M; Raja, U; Darr, W. and Bouckenooghe, D. (2014), "Combined Effects of Perceived Politics and Psychological Capital on Job Satisfaction, Turnover Intentions, and Performance", Journal of Management, Vol. 40, No. 7, pp. 1813-1830.

- Avey, J. B.; Patera, J. L. and Bradley, J. W. (2006), "The implications of positive psychological capital on employee absenteeism" Journal of Leadership \& Organizational Studies, 13 (2), $42-60$.

- Avey, J. B; Nimnicht, J. L and Nancy, G, P. (2010), "Two field studies examining the association between positive psychological capital and employee performance", Leadership \& Organization Development Journal, Vol. 31 Issue: 5, pp.384-401

- Avey, J.B.; Kuthans, F. and Jensen, S.M. (2009), "Psychological capital: a positive resource for combating employee stress and turnover", Human Resource Management, Vol. 48 No. 5, pp. 677-693.

- Bandura, A. (1994), "Self-efficacy", in Ramachandran, V.S. (Eds), Encyclopedia of Human Behavior, Academic Press, San Diego, CA, Vol. 4, pp. 71-81.

- Blomme, R. J.; Van Rheede, A. V. and Tromp, D. M. (2010) " The use of the psychological contract to explain turnover intentions in the hospitality industry: a research study on the impact of gender on the turnover intentions of highly educated employees", The International Journal of Human Resource Management, vol. 21(1), pp. 144-162.

- Cataldo, P. (2011), "Focusing on Employee Engagement: How to Measure It and Improve It", UNC Kenan-Flagler business school, All Content (9) UNC Executive Development, www.execdev.unc.edu

- Cunnien, K. A.; MartinRogers, N. and Mortimer, J. T. (2009), "Adolescent work experience and self-efficacy", International Journal of Sociology and Social Policy, Vol. 29 Issue: 3/4, pp.164-175.

- Gu, B. (2016), "Effects of psychological capital on employee turnover intentions: A study based on Hai Di Lao Hot Pot", Journal of Global Tourism Research, Vol. 1, No. 1. Pp.21:28.

- Hair, J. F.; Hult, J. T. M.; Ringle, C. M. and Sarstedt, M. (2017), "A Primer on Partial Least Squares Structural Equation Modeling (PLS-SEM)", Library of Congress Cataloging-in-Publication Data, SAGE Publications, Inc., UNS, Second Edition

- Han, Y; Brooks, I. N. K; Peng, Z. and Zhu, Y. (2012), "A grounded investigation of Chinese employees' psychological capital", Journal of Managerial Psychology, Vol. 27 Issue: 7, pp.669-695.

- Hinkin, T. R. and Tracey, J. B. (2000), "The cost of turnover: Putting a price on the learning curve", The Cornell Hotel and Restaurant Administration Quarterly, vol. 41, No.3, pp. 14-21.

- Joo, B. K; Lim, D. H and Kim, S. (2016), "Enhancing work engagement: The roles of psychological capital, authentic leadership, and work empowerment", Leadership \& Organization Development Journal, Vol. 37 Issue: 8, pp.1117-1134.

- Jung, H. S. and Yoon, H. H. (2015), "The impact of employees' positive psychological capital on job satisfaction and organizational citizenship behaviors in the hotel", International Journal of Contemporary Hospitality Management, Vol. 27 Issue: 6, pp.1135-1156

- Karatepe, O. M. and Karadas, G. (2015), "Do psychological capital and work engagement foster frontline employees' satisfaction?: A study in the hotel industry", International Journal of Contemporary Hospitality Management, Vol. 27 Issue: 6, pp.1254-1278.

- Karatepe, O. S.; Arasli, H. and Khan. A. (2007), "The Impact of Self-Efficacy on Job Outcomes of Hotel Employees: Evidence from Northern Cyprus", International Journal of Hospitality \& Tourism Administration, Vol. 8, No.4, pp. 23:46. 
- Lub. X; Bijvank, M. N; Bal, M. P; Blomme, R; Schalk, R. (2012) "Different or alike?: Exploring the psychological contract and commitment of different generations of hospitality workers", International Journal of Contemporary Hospitality Management, Vol. 24 Issue: 4, pp.553-573

- Luthans, F. and Youssef, C.M. (2004), "Human, social and now positive psychological capital management: investing in people for competitive advantage", Organizational Dynamics, Vol. 33, No.2, pp.143-160.

- Luthans, F.; Avolio, B.J.;Avey, J. and Norman, S.M. (2007b), "Psychological capital: measurement and relationship with performance and satisfaction", Personnel Psychology, Vol. 60, pp. 541-72.

- Luthans, F.; Avolio, B.J.; Walumbwa, F.O. and Li, W. (2005), "The psychological capital of Chinese workers: Exploring the relationship with performance", Management and Organization Review, Vol. 1, No.2, pp. $249-271$.

- Luthans, F.; Norman, S.M.; Avolio, B.J. and Avey, J.B. (2008), "The mediating role of psychological capital in the supportive organizational climate-employee performance relationship", Journal of Organizational Behavior, 29, 219-238.

- Luthans, F.; Vogelgesang, G. R. and Lester, P. B. (2006), "Developing the Psychological Capital of Resiliency", Human Resource Development Review Vol. 5, No. 1, pp.25-44.

- Luthans, F.; Youssef, C. M. and Avolio, B. J. (2007a), "Psychological capital: Developing the human competitive edge", Oxford University Press, Oxford UK.

- Lyons T. S. (2002), "Building social capital for rural enterprise development: Three case studies in the United States", Journal of Developmental Entrepreneurship, 7, 193-216.

- Masten, A. S.; Cutuli, J.J; Herbers, J.E; \& Reed, M. G. J. (2009), “chapter.12, Resilience in development”, Book of "The Oxford Handbook of Positive Psychology", edited by Snyder, C.R. and Lopez, S.J, Oxford University Press, pp. 117-131.

- McMurray, A. J; Pirola-Merlo, A; Sarros, J.C. and Islam, M.M. (2010), "Leadership, climate, psychological capital, commitment, and wellbeing in a non-profit organization", Leadership \& Organization Development Journal, Vol. 31 Issue: 5 , pp.436-457

- Onsoyen, L. E.; Mykletun, R. J. and Steiro, T. J. (2009) "Silenced and Invisible: The Work-experience of Room-attendants in Norwegian Hotels", Journal Scandinavian Journal of Hospitality and Tourism, Vol. 9, No. 1, pp. $81-102$

- Pengera, S. and Černe, M. (2014), “Authentic leadership, employees' job satisfaction, and work engagement: a hierarchical linear modelling approach", Economic Research-Ekonomska Istraživanja,Vol. 27, No. 1, pp.508-526.

- Preacher, K. J. and Hayes, A. F. (2008), "Asymptotic and resampling strategies for assessing and comparing indirect effects in multiple mediator models", Behavior Research Methods, Vol. 40, No.3, pp. 879-891.

- Abu Bakar, R. (2013) "Understanding Factors Influencing Employee Engagement: A Study of the Financial Sector in Malaysia", PhD thesis, School of Management Business Portfolio RMIT University, Malaysia.

- Romeo, E.J. and Cruthirds, K.W. (2006), "The use of humor in the workplace", Academy of Management Perspectives, Vol. 20 No. 2, pp. 58-69.

- Saks, A. M. (2006), “Antecedents and Consequences of Employee Engagement”, Journal of Managerial Psychology, Vol. 21, No. 7, pp. 600-619.

- Schaufeli, W. B. and Bakker, A. B. (2004), "Job demands, job resources, and their relationship with burnout and engagement: A multi sample study", Journal of Organizational Behavior, Vol. 25, pp.293-315.

- Schaufeli, W. B.; Salanova, M.; Vicente, G.A. and Bakker, A.B. (2002), "The Measurement of Engagement and Burnout: A Two Sample Confirmatory Factor Analytic Approach”, Journal of Happiness Studies, vol. 3, pp. 71 92.

- Siu, O. L.; Cheung, F. and Lui, S, (2015), "Linking Positive Emotions to Work Well-Being and Turnover Intention Among Hong Kong Police Officers: The Role of Psychological Capital", J Happiness Stud, Vol.16, pp.367-380.

- Tamer, I.; Dereli, B.; and saglam , M. (2014) " Unorthodox Forms of Capital in Organizations: Positive Psychological Capital, Intellectual Capital and Social Capital", Procedia - Social and Behavioral Sciences, Vol. 152, No.7, pp. 963-972.

- Thompson, K.R.; Lemmon, G.; and Walter, T. J. (2015) "Employee Engagement and Positive Psychological Capital ", Organizational Dynamics, vol. 44, pp. 185-195.

- Walker, A. and Campbell, K. (2013), "Work readiness of graduate nurses and the impact on job satisfaction, work engagement and intention to remain", Nurse Education Today, V/ol. 33, pp.1490-1495.

\title{
The impact of the positive psychological capital on the turnover intention of employees at some Egyptian Hotels using work engagement as a mediator
}

Mohammed Zeina Sameh Fayyad

Faculty of Tourism and Hotels, Suez Canal University

\begin{abstract}
This study aims at exploring the effect of Psychological capital (Psycap) on the turnover intention mediated by work engagement. The research was conducted on five-star hotels (20 out of 43) in Sharm El-Sheikh city. The study revealed high rates of employee turnover intention, a significant effect of (Psycap) dimensions on reducing turnover intention. Work engagement existence strengthens the relationship between (Psycap) and turnover intention. The study recommends considering the physical aspect parallel to the psychological aspect to reduce the turnover intention dilemma.
\end{abstract}

Keywords: Psycap- work engagement- turnover intention- Self-efficacy- Absorption. 